\title{
Nota Científica: Utilização da pectina, proteínas do soro de queijo e água de maceração de milho para a produção de proteases por Bacillus sp. termofílico
}

Scientific Note: Use of pectin, whey protein and corn steep liquor for the production of protease by thermophilic Bacillus sp.

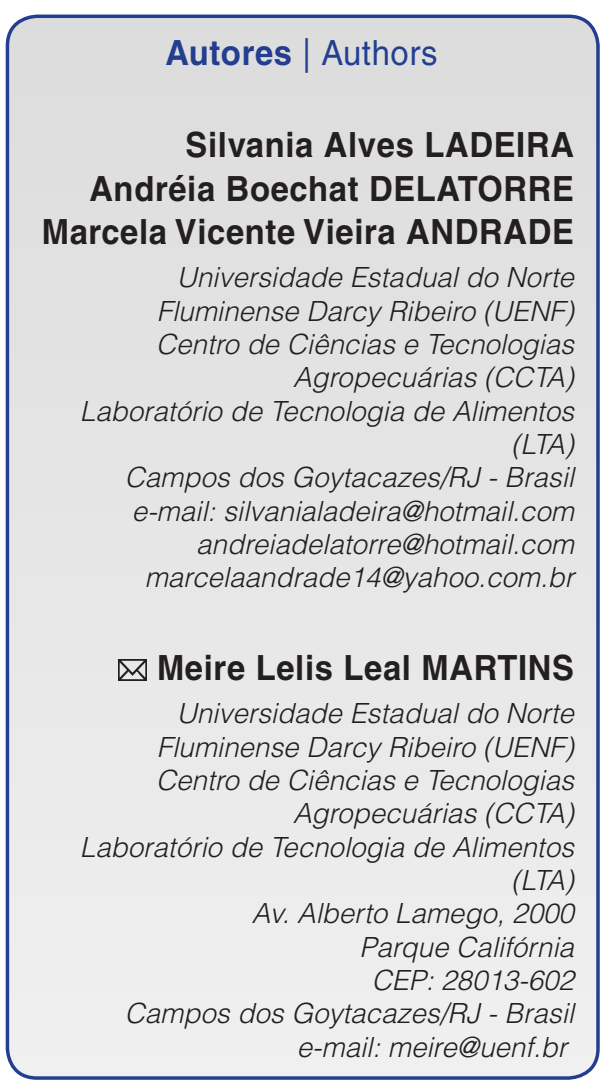

Autor Correspondente / Corresponding Author

Recebido / Received: 29/06/2009 Aprovado / Approved: 04/10/2011 Publicado / Published: mar./2012

\section{Resumo}

As enzimas proteolíticas termoestáveis produzidas por microrganismos do gênero Bacillus possuem grande importância comercial, sendo sua aplicação predominante $(35 \%)$ na indústria de detergentes. Neste trabalho, foi avaliada a produção de proteases pelo termofílico Bacillus sp. SMIA-2, utilizando-se substratos de baixo custo. A fim de verificar a utilidade da protease para aplicações industriais, a estabilidade e a atividade da enzima a diferentes valores de $\mathrm{pH}$ e temperatura foram também estudadas. A atividade da protease secretada por Bacillus sp. SMIA-2 em culturas submersas contendo 0,5\% (m/v) de pectina de maçã, $0,1 \%(\mathrm{~m} / \mathrm{v})$ de proteínas do soro e $0,3 \%(\mathrm{~m} / \mathrm{v})$ de água de maceração de milho foi máxima após 24 h de incubação da cultura, com níveis de 54,3 U.mg ${ }^{-1}$ Proteína. A redução na concentração da pectina para 0,3\% (m/v) e o aumento nos níveis das proteínas do soro para $0,3 \%(\mathrm{~m} / \mathrm{v})$ no meio de cultura aumentaram a produção da protease, que alcançou sua máxima atividade em 30 h, com níveis de 72,2 U. mg $^{-1}$ Proteína. Estudos sobre a protease revelaram que as suas características mais importantes foram a alta temperatura ótima para atividade da enzima $\left(70^{\circ} \mathrm{C}\right)$ e a alta estabilidade em uma grande faixa de $\mathrm{pH}$. A protease reteve em torno de $80 \%$ de sua atividade original quando incubada à temperatura ambiente por $2 \mathrm{~h}$ na faixa de $\mathrm{pH}$ entre 6,0 e 12,0. Essas propriedades constituem importantes vantagens para um possível uso da enzima em indústrias de detergentes.

Palavras-chave: Proteases; Bacillus sp.; Bactéria termofílica; Detergentes.

\section{Summary}

The thermostable proteolytic enzymes produced by the genus Bacillus are commercially very important, being predominantly applied (35\%) in detergents. In this work the production of proteases by a thermophilic Bacillus sp. SMIA-2 using low-cost substrates was evaluated. In order to assess the use of the protease for industrial use, the stability of the enzyme activity at different $\mathrm{pH}$ values and temperatures was also studied. The protease activity secreted by Bacillus sp. SMIA-2 in submerged cultures containing $0.5 \%(\mathrm{w} / \mathrm{v})$ apple pectin, $0.1 \%(\mathrm{w} / \mathrm{v})$ whey protein concentrate and $0.3 \%(\mathrm{w} / \mathrm{v})$ corn steep liquor reached a maximum after $24 \mathrm{~h}$, with levels of $54.3 \mathrm{U} . \mathrm{mg}^{-1}$ protein. A reduction in the pectin concentration to $0.3 \%(\mathrm{w} / \mathrm{v})$ and increase in the whey protein levels to $0.3 \%(\mathrm{w} / \mathrm{v})$ in the culture medium improved the protease production, which reached a maximum after $30 \mathrm{~h}$, with levels of $72.2 \mathrm{U} \cdot \mathrm{mg}^{-1}$ protein. Studies on the characterization of the protein revealed that the most important kinetic properties of the enzyme were the high optimal temperature $\left(70{ }^{\circ} \mathrm{C}\right)$ and high stability in a very broad $\mathrm{pH}$ range. The protease retained about $80 \%$ of its original activity when incubated at room temperature for $2 \mathrm{~h}$ in a $\mathrm{pH}$ range between 6.0 - 12.0. These properties represent important advantages for the possible use of the enzyme in detergent industries.

Key words: Proteases; Bacillus sp. Thermophilic bacterium; Detergents. 


\section{Introdução}

Proteases constituem um dos mais importantes grupos de enzimas industriais e têm aplicação em diferentes indústrias, como de alimentos, têxtil, farmacêutica e de detergentes (SINGH et al., 2003; MAURER, 2004; JOO e CHANG, 2005). A venda dessas enzimas representa cerca de $65 \%$ do total de enzimas comercializadas no mundo (VISHWANATHA et al., 2010).

Proteases termoestáveis produzidas por microrganismos do gênero Bacillus são o grupo mais importante de enzimas produzidas comercialmente (ASHGER, 2007). Os microrganismos desse gênero são capazes de se desenvolver em condições extremas de temperatura e $\mathrm{pH}$, o que permite a produção dessas enzimas em uma ampla faixa de $\mathrm{pH}$ e temperatura (WANG et al., 2007). A maior parte das bactérias pertencentes ao gênero Bacillus sp. apresenta uma variedade de sistemas de enzimas hidrolíticas e são capazes de utilizar substâncias orgânicas típicas de resíduos. Alem disso, com exceção do grupo Bacillus cereus, são saprófitas inofensivos, que não produzem toxinas e são incluídos no grupo de organismos geralmente reconhecidos como seguros (MAHMOOD et al., 1998).

Apesar das vantagens que as enzimas de microrganismos termofílicos do gênero Bacillus sp. oferecem para o uso rotineiro na indústria, a aplicação biotecnológica desses microrganismos tem sido muito limitada até agora. As razões para essa contradição são muitas, mas a principal delas está relacionada com o escasso número de linhagens termofílicas para a pesquisa de enzimas termoestáveis específicas, disponíveis em coleções (AQUINO, 2003).

O elevado custo da produção de enzimas é o principal obstáculo para sua aplicação industrial (GODFREY e WEST, 1996). Considerando-se que o substrato para o desenvolvimento desses microrganismos corresponde à faixa de 30 a 40\% do custo da produção de enzimas em escala industrial (JOO e CHANG, 2005), a pesquisa de metodologias e substratos alternativos é importante para a indústria (ASHIS et al., 2008; DIAS et al., 2008; PELIZER et al., 2007). Assim, este estudo avaliou a produção de proteases por Bacillus sp. termofílico SMIA-2, cultivado em pectina, proteínas do soro de leite e água de maceração de milho. Algumas propriedades das proteases, como estabilidade e atividade a diferentes valores de temperatura e $\mathrm{pH}$ foram também determinadas, a fim de se avaliar o potencial das enzimas para aplicações industriais.

\section{Material e métodos}

\subsection{Organismo e condições da cultura}

O microrganismo usado neste estudo foi uma bactéria termofílica, Bacillus sp., cepa SMIA-2, previamente isolada de amostras de solo coletadas na cidade de Campos dos Goytacazes-Rio de Janeiro, Brasil (NUNES e MARTINS, 2001).

O meio de cultura utilizado para a produção da protease continha $\left(g \cdot \mathrm{L}^{-1}\right)$ : pectina de maçã - 5,0; concentrado de proteínas do soro de queijo - 1,0; água de maceração de milho - 3,0; $\mathrm{KCl}-0,3 ; \mathrm{MgSO}_{4}$ - 0,5; $\mathrm{K}_{2} \mathrm{HPO}_{4}-0,87 ; \mathrm{CaCl}_{2}-0,29 ; \mathrm{ZnO}-2,03 \times 10^{-3}$; $\mathrm{FeCl}_{3} \cdot 6 \mathrm{H}_{2} \mathrm{O}-2,7 \times 10^{-2} ; \mathrm{MnCl}_{2} \cdot 4 \mathrm{H}_{2} \mathrm{O}-1,0 \times 10^{-2}$; $\mathrm{CuCl}_{2} \cdot 2 \mathrm{H}_{2} \mathrm{O}-8,5 \times 10^{-4} ; \mathrm{CoCl}_{2} \cdot 6 \mathrm{H}_{2}^{2} \mathrm{O}-2,4 \times 10^{-3}$; $\mathrm{NiCl}_{3} \cdot 6 \mathrm{H}_{2} \mathrm{O}-2,5 \times 10^{-4} \mathrm{e}_{3} \mathrm{BO}_{3}-3,0 \times 10^{-4}$. Posteriormente, esse meio foi modificado, reduzindo-se a concentração da pectina de maçã para $3,0 \mathrm{~g} \cdot \mathrm{L}^{-1}$ e aumentando a concentração das proteínas do soro para 3,0 g.L $\mathrm{L}^{-1}$.

$\mathrm{O} \mathrm{pH}$ dos meios foi ajustado para 7,0 com $\mathrm{NaOH}$ $1,0 \mathrm{M}$ e estes foram esterilizados em autoclave a $121+2^{\circ} \mathrm{C}$ por $15 \min$.

O meio de produção (50 mL em frascos Erlenmeyer de $250 \mathrm{~mL}$ ) foi inoculado com 0,1\% (m/v) de inóculo e incubada a $50^{\circ} \mathrm{C}$ em um agitador Thermo Forma Orbital Shaker (Ohio, USA) operado a $150 \mathrm{rpm}$. A intervalos de tempo determinados, foram retirados frascos em triplicata para medida do $\mathrm{pH}$ e da densidade ótica a $600 \mathrm{~nm}$, com a utilização de um espectrofotômetro Hitachi modelo U-2000.

\subsection{Ensaio enzimático}

Para a remoção das células, o meio de cultura foi centrifugado a $15.500 \mathrm{~g}$ por $15 \mathrm{~min}$ a $4{ }^{\circ} \mathrm{C}$, em uma centrífuga modelo HERMLEZ $382 \mathrm{~K}$ (Wehingen, Germany), e o sobrenadante livre de células foi utilizado para dosagem da atividade da enzima.

A atividade enzimática foi determinada em triplicata pela quantificação de peptídeos solúveis em ácido tricloroacético (TCA) 15\% (JANSEN et al., 1994). O substrato utilizado para essa determinação foi uma solução de azocaseína $0,2 \%(\mathrm{~m} / \mathrm{v})$, preparada em tampão Tris/ $\mathrm{HCl}(\mathrm{pH} 8,5 ; 0,2 \mathrm{M})$. Uma mistura contendo $0,5 \mathrm{~mL}$ do extrato enzimático e 1,0 mL do substrato foi incubada em banho-maria a $70{ }^{\circ} \mathrm{C}$ por 10 min. A reação foi paralisada pela adição de $0,5 \mathrm{~mL}$ de TCA e a solução centrifugada a $15.000 \mathrm{~g}$ por 5 min a $4{ }^{\circ} \mathrm{C}$. O mesmo procedimento foi realizado com o branco, exceto que o TCA foi adicionado antes do extrato enzimático. Uma unidade foi definida como a quantidade da enzima requerida para produzir um aumento na absorvância a 420 nm igual a 0,1 em 60 min. A concentração de proteínas foi determinada pelo método descrito por Peterson (1977).

\subsection{Efeito do $\mathrm{pH}$ na atividade e na estabilidade da protease}

A influência do $\mathrm{pH}$ sobre a atividade da protease foi avaliada na faixa de 6,0 a 12,0, com intervalo de 0,5 
Utilização da pectina, proteínas do soro de queijo e água de maceração de milho para a produção de proteases por Bacillus sp. termofílico

LADEIRA, S. A. et al.

unidade. Para o preparo do substrato, foi utilizada uma mistura tamponante contendo os seguintes tampões (0,2 M): fosfato de sódio, $\mathrm{pH}$ 6,0-8,0; Tris/HCl, pH 8,5-10,0, e glicina- $\mathrm{NaOH}$, $\mathrm{pH}$ 10,5-12,0.

$\mathrm{O} \mathrm{pH}$ ótimo foi determinado utilizando-se o substrato (azocaseína 0,2\% m/v) preparado nas soluções tampões com diferentes valores de $\mathrm{pH}$ e medindo-se a atividade enzimática conforme descrito anteriormente.

A estabilidade da protease a diferentes valores de $\mathrm{pH}$ foi avaliada incubando-se o extrato enzimático nos tampões já descritos, sem o substrato, por 2 h à temperatura ambiente. Após esse tratamento, a atividade residual da protease foi determinada segundo descrito anteriormente.

\subsection{Efeito da temperatura na atividade e na estabilidade da protease}

A determinação da temperatura ótima para a atividade enzimática foi alcançada realizando-se o ensaio enzimático descrito anteriormente em temperaturas que variaram de 40 a $100^{\circ} \mathrm{C}$, com intervalos de $10^{\circ} \mathrm{C}$.

A estabilidade térmica foi avaliada incubando-se a enzima em temperaturas que variaram de 40 a $100{ }^{\circ} \mathrm{C}$, com intervalos de $10^{\circ} \mathrm{C}$ por $2 \mathrm{~h}$. Posteriormente, para cada temperatura, a atividade residual foi analisada à temperatura ótima da enzima, determinada anteriormente (NASCIMENTO e MARTINS, 2004).

$\mathrm{O}$ efeito do íon $\mathrm{Ca}^{+2}$ sobre a atividade da enzima foi verificado incubando-se o extrato enzimático a $60{ }^{\circ} \mathrm{C}$ na presença e na ausência de $\mathrm{CaCl}_{2}(10 \mathrm{mM})$ por $3 \mathrm{~h}$.
Após intervalos de 15 min, foram retiradas amostras em triplicata para a determinação da atividade enzimática residual, conforme descrito anteriormente.

\section{Resultados e discussão}

\subsection{Perfil do crescimento do microrganismo e atividade proteásica}

O crescimento do Bacillus sp. SMIA-2 e a atividade da protease em meio líquido contendo pectina de maçã $(0,5 \% \mathrm{~m} / \mathrm{v})$, proteínas do soro $(0,1 \% \mathrm{~m} / \mathrm{v})$ e água de maceração de milho $(0,3 \% \mathrm{~m} / \mathrm{v})$ em função do tempo de fermentação são mostrados na Figura 1. A produção enzimática teve início após 6 h de incubação da cultura e foi aumentando com o desenvolvimento microbiano, atingindo valor máximo após $24 \mathrm{~h}$, com níveis de 54,3 U.mg ${ }^{-1}$ proteína. De acordo com Ward (1985), os microrganismos do gênero Bacillus geralmente produzem maiores quantidades de proteases ao final da fase exponencial de crescimento, acrescentando que a função dessas enzimas ainda não é bem conhecida, mas sua produção está correlacionada com uma elevada taxa de renovação de proteínas durante a esporulação.

Após alcançar o valor máximo, a atividade da protease decresceu, atingindo cerca de 58 e 10\% da atividade máxima em 42 e 54 h de crescimento, respectivamente. Esses resultados sugerem que tal comportamento da protease não é satisfatório, uma vez que poderia comprometer a sua produção em larga escala, pois o período em que essa enzima permaneceu estável foi curto. Esse processo de

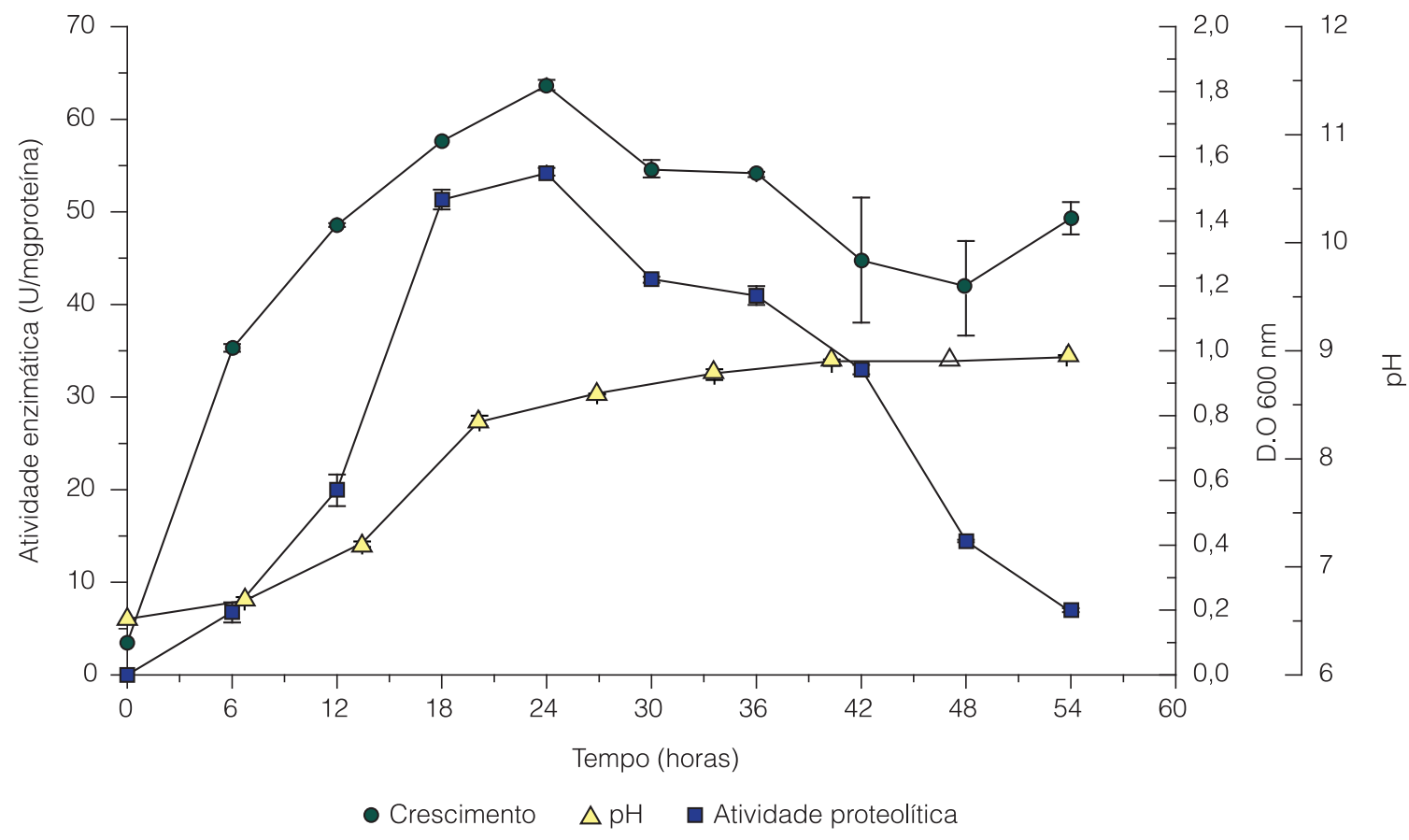

Figura 1. Crescimento, $\mathrm{pH}$ e atividade proteolítica em função do tempo em culturas de Bacillus sp. SMIA-2, cultivado em meio líquido por $48 \mathrm{~h}$ a $50^{\circ} \mathrm{C}$. As barras representam o desvio padrão. A ausência de barras indica que o erro foi menor do que o símbolo. 
Utilização da pectina, proteínas do soro de queijo e água de maceração

de milho para a produção de proteases por Bacillus sp. termofílico

LADEIRA, S. A. et al.

inativação, que é característico na produção de proteases por microrganismos, torna difícil a produção enzimática em larga escala, em razão da dificuldade de se isolar a enzima em sua atividade máxima (NASCIMENTO et al., 2007). Vários pesquisadores conseguiram aumentar a estabilidade da protease por meio de modificações no meio de crescimento, como o aumento da concentração do cálcio, a remoção de agentes quelantes e a diminuição da concentração de fosfato de potássio, sem, contudo, prejudicar o crescimento do microrganismo (BAKHTIAR et al., 2002; GHORBEL et al., 2003; AZEREDO et al., 2004).

A redução da concentração da pectina de maçã de $0,5 \%(\mathrm{~m} / \mathrm{v})$ para $0,3 \%(\mathrm{~m} / \mathrm{v})$ e o aumento da concentração das proteínas do soro de $0,1 \%(\mathrm{~m} / \mathrm{v})$ para $0,3 \%(\mathrm{~m} / \mathrm{v})$ promoveram um acréscimo nos valores da atividade da protease a partir de $18 \mathrm{~h}$ de incubação da cultura (Figura 2). Além disso, a enzima foi estável entre 18 e $36 \mathrm{~h}$ de incubação da cultura e, em 54 h, foi observada uma redução de apenas 30\% na atividade da enzima, o que é de grande importância para a sua produção em larga escala. Tanto a água de maceração do milho, resultante do processamento dos grãos de milho, como as proteínas do soro, extraídas durante o processo de fabricação de queijo, são subprodutos ricos em aminoácidos, peptídeos e minerais, e são de baixo custo.

Um decréscimo da densidade ótica da cultura foi observado quando o meio foi modificado. A máxima densidade ótica obtida no meio anterior foi $1,8 \mathrm{com} 24 \mathrm{~h}$ de incubação do microrganismo, enquanto que, no meio modificado, a máxima densidade ótica foi de $1,2 \mathrm{com} 30 \mathrm{~h}$ de incubação da cultura. Dessa maneira, as condições que favoreceram o crescimento celular foram diferentes daquelas que estimularam a produção da protease, demonstrando a natureza complexa do processo bioquímico envolvido na obtenção dessa enzima.

$\mathrm{O}$ pH do meio aumentou com o início do desenvolvimento microbiano e da produção da protease, provavelmente em função do consumo de nitrogênio orgânico, como aminoácidos e peptídeos, e estabilizou prestes a atingir o valor de 9,0 após a enzima alcançar sua máxima atividade. Por causa dessa relação entre o $\mathrm{pH}$ e a síntese de proteases, a variação do $\mathrm{pH}$ pode ser utilizada para fornecer informações importantes sobre a produção da enzima, como o início e o final de sua síntese.

\subsection{Efeito do $\mathrm{pH}$ na atividade e na estabilidade da protease}

A protease foi ativa em uma ampla faixa de $\mathrm{pH}$, apresentando máxima atividade $\left(100 \%=62,8 \mathrm{U} \cdot \mathrm{mg}^{-1}\right.$ proteína) em torno de pH 8,5 (Figura 3). De acordo com Beg e Gupta (2003), as proteases comerciais de origem microbiana geralmente possuem atividade ótima na faixa de $\mathrm{pH}$ que varia de 8,0 a 12,0, o que as torna de grande interesse para utilização em formulações de detergentes, em função do $\mathrm{pH}$ alcalino desses produtos.

Em relação à estabilidade ao $\mathrm{pH}$, a enzima foi estável em uma ampla faixa de $\mathrm{pH}$, mantendo aproximadamente $85 \%$ de sua atividade máxima quando incubada por $2 \mathrm{~h}$ na faixa de $\mathrm{pH}$ compreendida entre 6,0 e 12 (Figura 3). Estes resultados possibilitam a aplicação

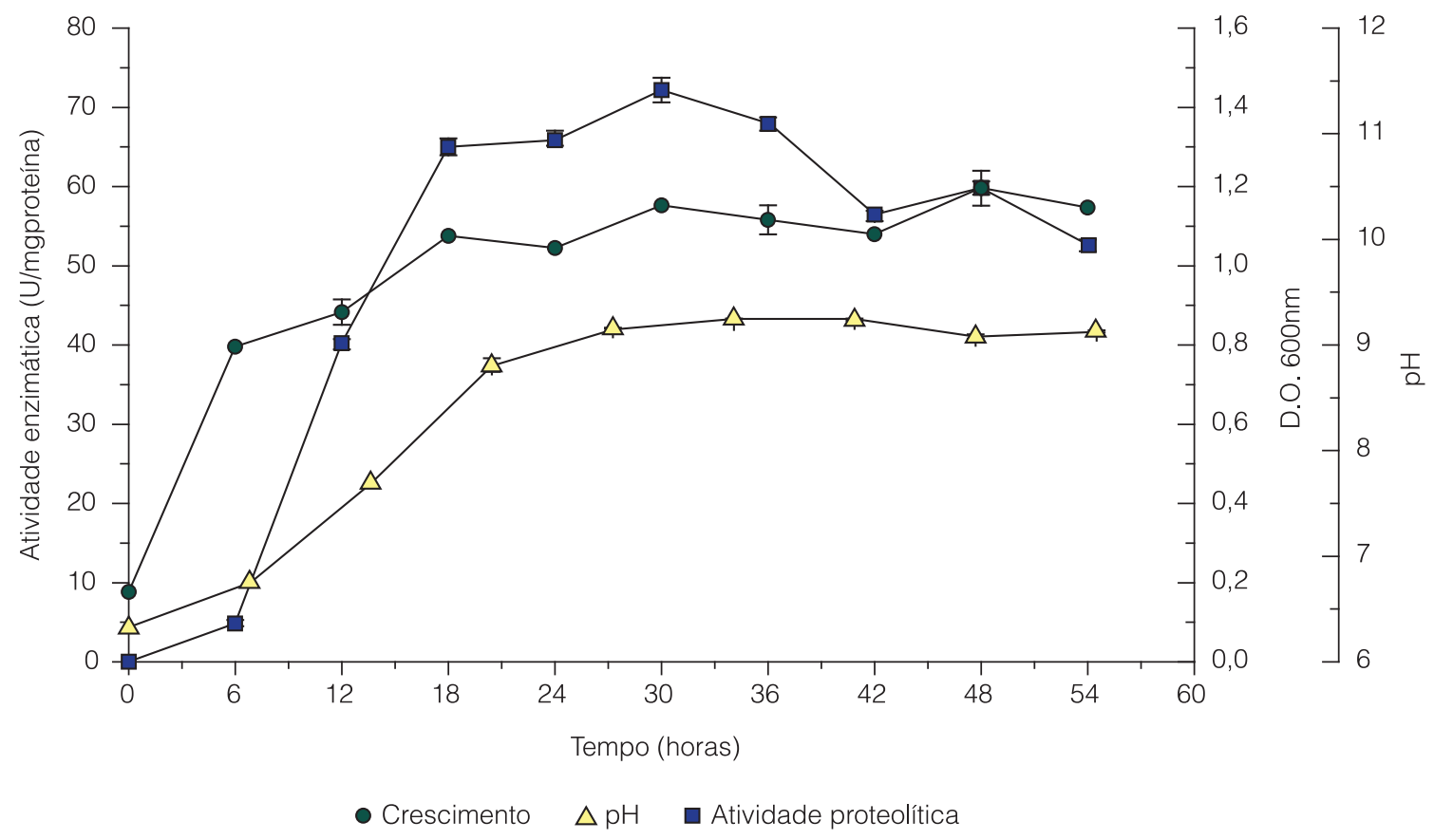

Figura 2. Crescimento, $\mathrm{pH}$ e atividade proteolítica em função do tempo em culturas de Bacillus sp. SMIA-2, cultivadas em meio líquido por $48 \mathrm{~h}$ a $50^{\circ} \mathrm{C}$. As barras representam o desvio padrão. A ausência de barras indica que o erro foi menor do que o símbolo. 


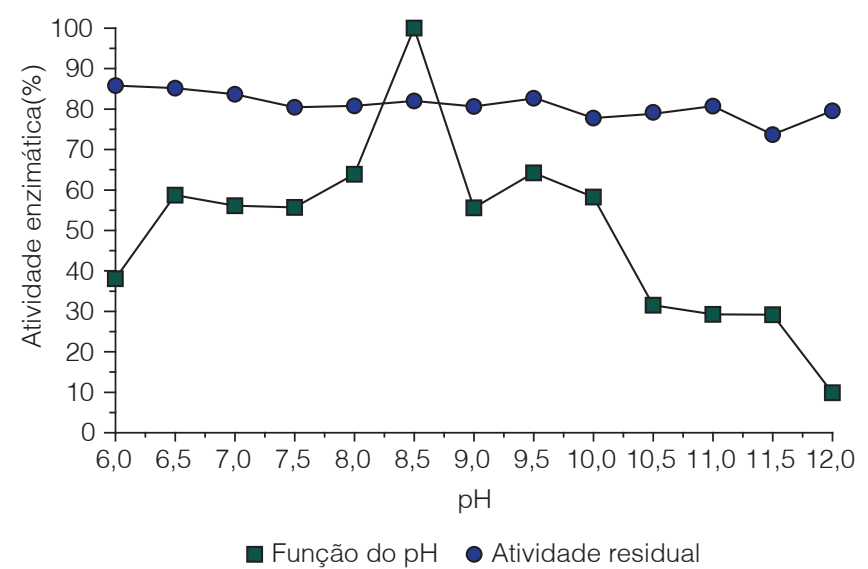

Figura 3. Atividade enzimática em função do pH e atividade residual após $2 \mathrm{~h}$ de incubação em diferentes $\mathrm{pH}$ s de protease de Bacillus sp. (100\% de atividade $=62,8$ U. $\mathrm{mg}^{-1}$ proteína).

da enzima em diversos setores industriais, incluindo a indústria de detergentes. O valor do pH de atuação de uma enzima é um importante parâmetro para se determinar a viabilidade de sua aplicação em um dado detergente. A atividade catalíticos em valores elevados de $\mathrm{pH}(10,0-11,0)$, ou mesmo moderadamente elevados $(8,0-9,0)$, indica que a enzima é bastante viável para ser utilizada em detergentes. A Alcalase ${ }^{\circledR}$, enzima muito utilizada na indústria de detergentes, possui pH ótimo de atuação na faixa de 8,0 a 9,0 (GODFREY e WEST, 1996).

\subsection{Temperatura ótima e estabilidade térmica}

A atividade da enzima aumentou com a elevação da temperatura, atingindo seu valor máximo a $70{ }^{\circ} \mathrm{C}$, conforme mostrado na Figura 4. Nas temperaturas de 80 e $90{ }^{\circ} \mathrm{C}$, a enzima apresentou 65 e $35 \%$ de sua atividade máxima, respectivamente. Em Bacillus licheniformis SMI 4. C.1., a melhor atividade de protease foi observada a $70{ }^{\circ} \mathrm{C}$ (MAURER, 2004).

A protease manteve em torno de $80 \%$ de sua atividade quando incubada por $2 \mathrm{~h}$ a $60{ }^{\circ} \mathrm{C}$ e reduziu drasticamente sua estabilidade a temperaturas mais altas. A incubação da enzima a 90 e $100{ }^{\circ} \mathrm{C}$ por $2 \mathrm{~h}$ resultou na completa inibição da atividade da protease.

Vários pesquisadores demonstraram que a adição de metais ao extrato bruto de algumas enzimas promove $\mathrm{o}$ aumento da sua termoestabilidade (JOO et al., 2002; GHORBEL et al., 2003; SINGH et al., 2003). De fato, foi observado, neste trabalho, que a incubação da enzima a $60{ }^{\circ} \mathrm{C}$ na presença de $10 \mathrm{mM} \mathrm{CaCl}{ }_{2}$ aumentou consideravelmente a sua atividade (Figura 5). Ghorbel et al. (2003) verificaram um aumento na termoestabilidade de uma protease produzida por Bacillus cereus BG1 quando incubada na temperatura de $60{ }^{\circ} \mathrm{C}$ em presença de $\mathrm{Ca}^{+2}$. De acordo com os autores, o papel do $\mathrm{Ca}^{+2}$ na estabilização da protease pode

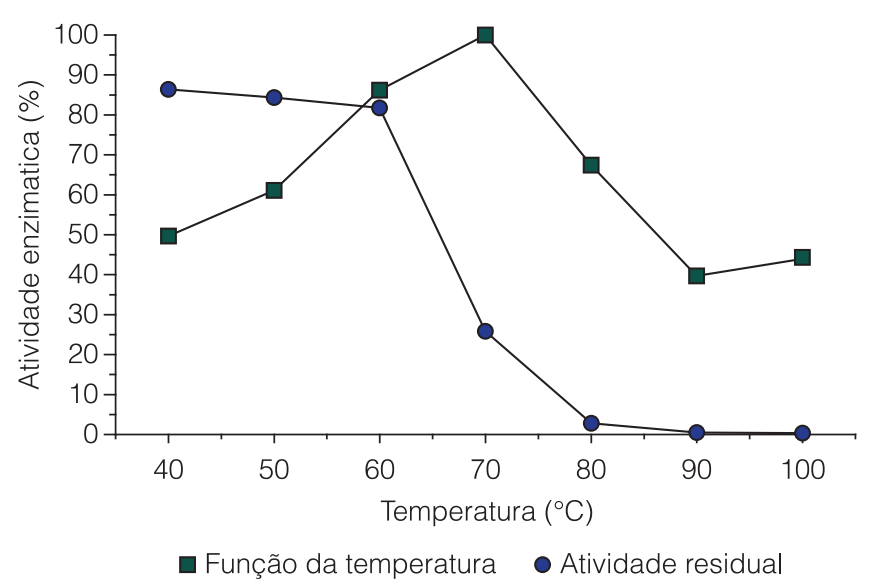

Figura 4. Atividade enzimática em função da temperatura e atividade residual após incubação por duas $2 \mathrm{~h}$ em diferentes temperaturas de protease de Bacillus sp. (100\% de atividade $=65,2 \cup \cdot \mathrm{mg}^{-1}$ proteína) .

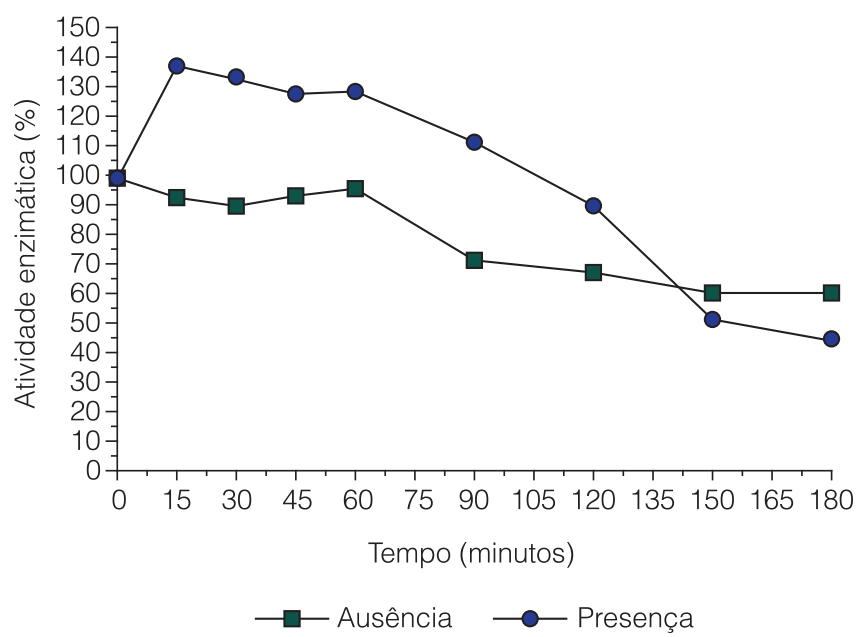

Figura 5. Atividade enzimática residual em função do tempo na ausência e na presença de $10 \mathrm{mM}$ de $\mathrm{CaCl}_{2}$ de protease de Bacillus sp. (100\% de atividade $=60,6$ U. $\mathrm{mg}^{-1}$ proteína).

ser explicado pela grande força de interação entre as moléculas de proteína, por causa da ligação desses íns no sítio ativo da mesma, impedindo sua desnaturação.

\section{Conclusões}

Os resultados mostraram o potencial do uso das proteínas do soro e da água de maceração de milho como meio de cultura para a produção de proteases por Bacillus sp SMIA-2. A enzima mostrou atividade ótima à temperatura de $70{ }^{\circ} \mathrm{C}$ e $\mathrm{pH} 8,5$, e foi estável na faixa de $\mathrm{pH}$ de 6,0 a 12,0. Essas propriedades constituem importantes vantagens para um possível uso da enzima na indústria de detergentes.

\section{Agradecimentos}

Os autores agradecem ao CNPq (Conselho Nacional de Desenvolvimento Científico e Tecnológico), 
Utilização da pectina, proteínas do soro de queijo e água de maceração de milho para a produção de proteases por Bacillus sp. termofílico

LADEIRA, S. A. et al.

pelo apoio financeiro, e à CAPES (Coordenação de Aperfeiçoamento de Pessoal de Nível superior), pela concessão de Bolsa de Mestrado.

\section{Referências}

AQUINO, A. C. M. M.; JORGE, J. A.; TERENZI, H. F.; POLIZELI, M. L. T. M. Studies on a thermostable $\alpha$-amylase from the thermophilic fungus Scytalidium thermophilum. Applied Microbiology and Biotechnology, Heidelberg, v. 61, n. 3, p. 323-328, 2003. http://dx. doi.org/10.1007/s00253-003-1290-y

ASHIS, K.; MUKHERJEE, H. A.; SUDHIR, K. R. Production of alkaline protease by a thermophilic Bacillus subtilis under solidstate fermentation (SSF) condition using Imperata cylindrical grass and potato peel as low-cost medium: Characterization and application of enzyme in detergent formulation. Biochemical Engineering Journal, London, v. 39, n. 2, p. 353-361, 2008. http://dx.doi.org/10.1016/j.bej.2007.09.017

ASHGER, M.; ASAD, M. J.; RAHMAN, S. U.; LEGGE, R. L. A thermostable $\alpha$-amylase from a moderately thermophilic Bacillus subtilis strain for starch processing. Journal of Food Engineering, New York, v. 79, n. 3, p. 950-955, 2007. http:// dx.doi.org/10.1016/j.jfoodeng.2005.12.053

AZEREDO, L. A. I.; FREIRE, D. M. G.; SOARES, R. M. A.; LEITE, S. G. F.; COELHO, R. R. R. Production and partial characterization of thermophilic proteases from Streptomyces sp. isolated from Brazilian cerrado soil. Enzyme and Microbial Technology, New York, v. 34, p. 354-358, 2004. http://dx.doi.org/10.1016/j. enzmictec.2003.11.015

BAKHTIAR, S.; ANDERSON, M. M.; GESSESSE, A.; MATTIASON, B.; KAUL, R. H. Stability characteristics of the CalciumIndependent alkaline protease from Nesterenkonia sp. Enzyme and Microbial Technology, New York, v. 32, n. 5, p. 525-531, 2002. http://dx.doi.org/10.1016/S0141-0229(02)00336-8

BEG, Q. K.; GUPTA, R. Purification and characterization of an oxidation-stable, thiol-dependent serine alkaline protease from Bacillus mojavensis. Enzyme and Microbial Technology, New York, v. 32, n. 2, p. 294-304, 2003. http://dx.doi.org/10.1016/ S0141-0229(02)00293-4

DIAS, D. R.; VILELA, D. M.; SILVESTRE, M. P. C.; SCHWAN, R. F. Alkaline protease from Bacillus sp. isolated from coffee bean grown on cheese whey. World Journal of Microbiology and Biotechnology, Oxford, v. 24, n. 9, p. 2027-2034, 2008. http:// dx.doi.org/10.1007/s11274-008-9706-6

GHORBEL, B.; KAMOUN, A. S.; NASRI, M. Stability studies of protease from Bacillus cereus BG1. Enzyme and Microbial Technology, New York, v. 32, n. 5, p. 513-518, 2003. http:// dx.doi.org/10.1016/S0141-0229(03)00004-8

GODFREY, T.; WEST, S. Industrial Enzimology. 2. ed. Stockton Press, 1996. $609 \mathrm{p}$.
JANSEN, P. H.; PEEK, K.; MORGAN, H. W. Effect of culture conditions on the production of a extracellular proteinase by Thermus sp. Rt41A. Applied Microbiology and Biotechnology, Heidelberg, v. 41, n. 4, p. 400-406, 1994. http://dx.doi. org/10.1007/BF00939027

JOO, H.S; CHANG, C.S. Production of protease from a new Alkalophilic Bacillus sp. I-312 grow on soybean meal: optimization and some properties. Process Biochemistry, Grã Bretanha, v. 40, n. 3-4, p. 1263-1270, 2005. http://dx.doi. org/10.1016/j. procbio.2004.05.010.

JOO, H. S.; KUMAR, C. G.; PARK, G. C.; KIM, T. K.; PAIK, S. R.; CHANG, C. S. Otimization of the production of an extracellular alkaline protease from Bacillus horikoshii. Process Biochemistry, Grã Bretanha, v. 38, n. 2, p. 155-159, 2002. http:// dx.doi.org/10.1016/S0032-9592(02)00061-4

MAHMOOD, A. U; GREENMAN, J.; SCRAGG, A. H. Orange and potato peel extracts: Analysis and use as Bacillus substrates for the production of extracellular enzymes in continuous culture. Enzyme Microbial and Technology, New york, v. 22, n. 2, p. 130-137, 1998. http://dx.doi.org/10.1016/S01410229(97)00150-6

MAURER, K. H. Detergents proteases. Current Opinion in Biotechnology, London, v.15, n. 3, p. 330-334, 2004. http:// dx.doi.org/10.1016/j.copbio.2004.06.005

NASCIMENTO, W. C. A.; MARTINS, M. L. L. Production and properties of an extracellular protease from thermophilic Bacillus sp. Brazilian J of Microbiology, São Paulo, v. 35, n. 1-2, p. 91-96, 2004. http://dx.doi.org/10.1590/S151783822004000100015

NASCIMENTO, W. C. A.; CARVALHO, R. V.; SILVA, C. R.; MARTINS, M. L. L. Otimização de um meio de cultura para produção de proteases por um Bacillus sp. Termofílico. Ciência e Tecnologia de Alimentos, São Paulo, v. 27, n. 2, p. 417-421, 2007. http://dx.doi.org/10.1590/S0101-20612007000200035

NUNES, A. S.; MARTINS, M. L. L. Isolation, properties and kinetics of growth of a thermophilic Bacillus. Brazilian Journal of Microbiology, São Paulo, v. 32, n. 3, p. 271-275, 2001. http:// dx.doi.org/10.1590/S1517-83822001000400003

PELIZER, L. H.; PONTIERI, M. H.; MORAES, I. O. Utilização de resíduos agro-industriais em processos biotecnológicos com perspectiva de redução do impacto ambiental. Journal of Technology Management \& Innovation, Santiago, v. 2, n. 1 , p. 118-127, 2007.

PETERSON, G. L. A simplification of the protein assay method of Lowry et al. which is more generally applicable. Analytical Biochemistry, New York, v. 83, n. 2, p. 346-356, 1977. http:// dx.doi.org/10.1016/0003-2697(77)90043-4

SINGH, J.; VOHRA, R. M.; SAHOO, D. K. Enhanced production of alkaline protease by Bacillus sphaericus using fed-batch culture. 
Utilização da pectina, proteínas do soro de queijo e água de maceração de milho para a produção de proteases por Bacillus sp. termofílico

LADEIRA, S. A. et al.

Process Biochemistry, Grã Bretanha, v. 39, n. 9, p. 1093-1098, 2003. http://dx.doi.org/10.1016/S0032-9592(03)00217-6

VISHWANATHA, K. S.; RAO, A. G. A.; SINGH, S. A. Acid protease production by solid-state fermentation using Aspergillus oryzae MTCC 5341: optimization of process parameters. Journal of Industrial Microbiology and Biotechnology, Heidelberg, v. 37, p. 129-138, 2010. http://dx.doi.org/10.1007/s10295-009-0654-4
WANG, Q.; FAN, X.; HUAB, Z.; CHENB, J. Optimizing bioscouring condition of cotton knitted fabrics with an alkaline pectinase from Bacillus subtilis WSHB04-02 by using response surface methodology. Biochemical Engineering Journal, London, v. 34, n. 1, p. 107-113, 2007. http://dx.doi.org/10.1016/j. bej.2006.11.004

WARD, O. P. Proteolytic enzymes. Comprehensive Biotechnology, Oxford, v. 3, n. 7, p. 789-818. 1985. 